Motrivivência $\quad$ v. 27, n. 46, p. 99-118, dezembro/2015

\title{
CONDIÇÕES DE TRABALHO, TEMPO DE CARREIRA E DIMENSÕES DA SAÚDE DE PROFESSORES DE EDUCAÇÃO FÍSICA DO ESPÍRITO SANTO
}

\author{
Mariana Pozzatti' \\ Silvana Ventorim² \\ Wagner dos Santos 3 \\ Amarílio Ferreira Neto ${ }^{4}$
}

\section{RESUMO}

Discute condições de trabalho, tempo de carreira e dimensões da saúde de 87 professores de Educação Física atuantes em cinco municípios do Espírito Santo (Guarapari, Nova Venécia, Santa Teresa, Viana e Vitória), participantes do survey da pesquisa nacional Trabalho Docente na educação básica do Brasil. Trata-se de um estudo quanti-qualitativo, de caráter descritivo e interpretativo, que se fundamenta na classificação dos ciclos/ fases/estágios da carreira docente de Huberman (2007) e dialoga, principalmente, com Santini $(2004$, 2005) e Almeida (2008). Conclui que a relação da condição de trabalho e tempo de carreira, analisados isoladamente, não determina a saúde e o mal-estar do profissional docente e que esse processo é complexo, dependendo de um conjunto de fatores que envolvem questões pedagógicas, profissionais e pessoais.

Palavras-chave: Professor de Educação Física; Condição Docente; Saúde

1 Doutoranda em Educação Física. UFES, Vitória/Espírito Santo, Brasil. E-mail: marianapozzatti@gmail.com

2 Doutora em Educação. Professora do Programa de Pós-Graduação em Educação (PPGE) e do Centro de Educação (CE). UFES, Vitória/Espírito Santo, Brasil. E-mail: silventorim@hotmail.com

3 Doutor em Educação. Professor do Programa de Pós-Graduação em Educação Física (PPGEF) do Centro de Educação Física e Desportos (CEFD). UFES, Vitória/Espírito Santo, Brasil. E-mail: wagner@proteoria.org

4 Doutor em Educação. Professor do Programa de Pós-Graduação em Educação Física do Centro de Educação Física e Desportos (CEFD). UFES, Vitória/Espírito Santo, Brasil. E-mail: amarilio@proteoria.org 


\section{INTRODUÇÃO}

Ser professor na contemporaneidade, assumindo-se como profissional cujo trabalho se fundamenta nas interações (TARDIF, 2002), integrado por elementos macro e microestruturais da escola e da própria sociedade, significa admitir uma complexidade de dimensões e aspectos constituintes que envolvem desde questões referentes às políticas educacionais até a prática pedagógica, a qual, por sua vez, não se esgota no desenvolvimento da aula. O trabalho docente tem assumido, assim, demandas cada vez mais diversificadas e suas condições consolidam-se em um cenário contraditório e, muitas vezes, precário.

Nos últimos anos, observamos um crescente interesse dos estudiosos em investigar as condições e interfaces do trabalho do professor. Ao realizar o estado do conhecimento na produção acadêmica sobre trabalho docente na educação básica no Brasil, utilizando como fonte dissertações e teses publicadas entre 1987-2007, Duarte (2010) identificou que essas análises podem ser realizadas sob os diferentes aspectos, tais como: identidade; formação, prática e saberes docentes; condições, processos e relações de trabalho, saúde e mal-estar docentes.

Na Educação Física, Pozzatti (2012) realizou um movimento investigativo na produção de dados da pesquisa nacional Trabalho docente na educação básica no Brasil (TDEBB) ${ }^{5}$ e constatou que os aspectos relacionados com a identidade e a trajetória pessoal e profissional do docente, assim como com o seu trabalho são alimentados por outros elementos, muitas vezes resultantes, principalmente, das condições que Ihes são possíveis no espaço escolar e da forma como a carreira se consolida ao longo dos anos. O estudo indicou que as condições de trabalho vividas pelos docentes de alguns municípios do Espírito Santo se assemelham às de outras regiões do país, principalmente em relação aos aspectos constituintes da docência, à formação, à infraestrutura, à carga horária fragmentada e à remuneração. Evidenciou, ainda, que essas condições podem determinar a permanência na carreira e apontou algumas lacunas como indicações de estudos futuros, entre as quais, a relação tempo de carreira e condições de saúde do trabalhador docente.

Os estudos de Cruz e Lemos (2005), Folle e Nascimento (2008) e Both e Nascimento (2009) também teceram considerações sobre a relação tempo de carreira e saúde do docente. Apesar de identificarem um crescente interesse nas discussões referentes às interfaces do trabalho docente na Educação Física, os próprios autores indicaram que esse debate ainda se apresenta como potencial para investigações referentes à carreira, à profissão, às condições de trabalho e de saúde.

Motivados por essas questões, concentramo-nos em discutir condições de trabalho, tempo de carreira e dimensões da saúde de professores de Educação Física atuantes nas escolas públicas de educação básica dos municípios de Guarapari, Nova Venécia, Santa Teresa, Viana e Vitória, reconhecendo a "[...] necessidade imperiosa

5 Informações sobre a pesquisa nacional podem ser consultadas em Oliveira et al. (2009) e no site http://trabalhodocente.net.br/. Já sobre a pesquisa no Espírito Santo, ver Bartolozzi, Oliveira e Vieira (2012) e Pozzatti (2012). 
de investigações que procurem contemplar a difícil equação entre a macrorrealidade dos sistemas educacionais e o cotidiano escolar [...] abarcando o contexto em que se desenvolvem" (OLIVEIRA, 2004, p. 1128).

Para tanto, compreendemos o trabaIho docente como aquele que realizamos na sala de aula e em outros momentos que envolvem o processo do ensino e da aprendizagem, como "[...] a participação do professor no planejamento das atividades, na elaboração de propostas político-pedagógicas e na própria gestão da escola [...]" (DUARTE et al., 2008, p. 222). Esse trabalho pode ser alimentado pelo reconhecimento social dos integrantes da própria comunidade escolar (sociedade, pais, equipe pedagógica e alunos).

Assim, ao analisarmos alguns aspectos das condições de trabalho em consonância com os ciclos da carreira recentemente utilizados por estudiosos da Educação Física, como Folle e Nascimento (2008), Both, Nascimento e Borgatto (2007) - e fatores relacionados com a saúde e o mal-estar docentes, este estudo tem como eixos investigativos apresentar as fases/ ciclos da carreira em que os professores se encontravam no período da investigação, discutir questões referentes à saúde desses profissionais e, por fim, relacioná-las com as condições de trabalho e carreira.

$\mathrm{Na}$ qualidade de interlocutores, dialogamos com Huberman (2007), que organiza o percurso profissional em fases/ ciclos/estádios de acordo com o tempo na profissão; com Santini (2004), que discute o processo de abandono da carreira docente pelos professores de Educação Física da rede municipal de ensino de Porto Alegre/ RS apresentando fatores da Síndrome do Esgotamento Profissional (SEP); e com Almeida (2008), que realiza uma análise da relação saúde-trabalho de professores de Educação Física de uma escola polivalente da Grande Vitória. ${ }^{6}$

\section{DECISÕES METODOLÓGICAS}

Trata-se de uma reflexão realizada na conclusão de uma dissertação de mestrado que foi desenvolvida no Centro de Educação Física e Desportos da Universidade Federal do Espírito Santo (Cefd/Ufes), em 2011 e 2012, e utilizou elementos do banco de dados da pesquisa nacional TDEBB, no que concerne ao trabalho docente na Educação Física no Espírito Santo. ${ }^{7}$ Tal reflexão se impulsiona pelos recorrentes apontamentos

6 Trata-se da região metropolitana, instituída em 1995 e composta pelos municípios de Cariacica, Fundão, Guarapari, Serra, Viana e Vitória (capital). Juntos, esses municípios representam significativa parcela da população e produção de riquezas do Estado do Espírito Santo.

7 Após aproximação com alguns professores participantes da pesquisa TDEBB e voltando-nos para a Educação Física, a dissertação objetivou compreender como o docente de Educação Física vem desenvolvendo seu trabalho nas escolas públicas de educação básica dos municípios investigados no Espírito Santo. Foi organizada em quatro capítulos: um primeiro com a apresentação do delineamento teórico-metodológico, denominado "Delineamento do estudo"; um outro, de caráter documental, com um estudo de revisão intitulado "Estado do conhecimento da produção acadêmica sobre a temática trabalho docente na Educação Física"; e dois outros capítulos com a produção dos dados do survey da pesquisa TDEBB: "Atores da Educação Física no Espírito Santo e trajetórias profissionais" e "Dimensões do trabalho docente na Educação Física no Espírito Santo". Combinando essas diferentes abordagens, tanto na análise documental quanto na produção do survey, a dissertação assumiu-se como estudo quanti-qualitativo. 
de outros estudos para a necessidade de investigar e discutir as condições de trabalho e saúde do docente, relacionando-as com as fases/ciclos da carreira, apresentados em Huberman (2007).

A pesquisa TDEBB, conforme explicitam Ferreira, Oliveira e Vieira (2012), focou na realização de um estudo documental sobre a política educacional nas redes de ensino envolvidas; em uma revisão de literatura sobre o tema trabalho docente com base na produção acadêmica na área; em um panorama do trabalho docente na educação básica no Brasil com dados estatísticos disponíveis na base do Instituto Nacional de Estudos e Pesquisas Educacionais Anísio Teixeira (Inep); e em um survey nacional sobre o trabalho docente na educação básica no Brasil em sete Estados e uma amostra de municípios.

Com isso, buscou analisar

[...] o trabalho docente nas suas dimensões constitutivas, identificando seus atores, o que fazem e em que condições se realiza o trabalho nas unidades de educação básica da rede pública e conveniada, tendo como finalidade subsidiar a elaboração de políticas públicas no Brasil, especificamente nos estados pesquisados (FERREIRA; OLIVEIRA: VIEIRA, 2012, p.11).

Investigando a realidade dos Estados do Pará, do Rio Grande do Norte, de Goiás, do Paraná, de Santa Catarina e do Espírito Santo em 2009, o estudo - coordenado nacionalmente pelo Grupo de Estudos sobre Política Educacional e Trabalho Docente da
Universidade Federal de Minas Gerais (Gestrado/UFMG) e, no Espírito Santo, pelo Núcleo de Estudos em Políticas Educacionais da Universidade Federal do Espírito Santo (Nepe/Ufes) - exigiu esforços de combinar as abordagens quantitativa (visão realista/ objetivista) e qualitativa (visão idealista/ subjetivista).

Os Estados e municípios foram selecionados utilizando o "[...] método de amostragem probabilística cuja amostra é representativa da população-alvo" (OLIVEIRA; VIEIRA, 2010, p. 16), combinado com a amostragem aleatória simples. Para a pesquisa de campo, depois de selecionadas as escolas, os sujeitos, ao aderirem ao estudo por livre consentimento, assinavam um termo e respondiam ao questionário à presença de um aplicador. ${ }^{8}$

Especificamente com dados coletados por meio do survey em 78 escolas de educação infantil, ensino fundamental e médio dos municípios de Vitória, Nova Venécia, Santa Tereza, Viana e Guarapari, foram entrevistados 1.481 profissionais da educação básica. Concentrando-nos nos 87 docentes de Educação Física atuantes nas escolas dos municípios capixabas que realizaram o survey (13 professores de Guarapari, correspondendo a $14,9 \%$; 5 professores de Nova Venécia, 5,7\%; 2 professores de Santa Teresa, 2,3\%; 13 professores de Viana, 14,9\%; e 54 professores de Vitória, $62,2 \%$ ), associando diretamente os objetivos e finalidades desta pesquisa, realizamos um estudo quanti-qualitativo (QUEIROZ, 2006), buscando entender além

8 Esses sujeitos foram previamente treinados pelas coordenações nacional e estadual do estudo.

9 A soma dos esforços desse momento da pesquisa TDEBB resultou em 8.895 questionários válidos aplicados. O Espírito Santo liderou o número de questionários por Estado, totalizando 1.481 indivíduos pesquisados. 
das situações investigadas e das generalizações resultantes do instrumento de coleta de dados utilizado na pesquisa de campo. ${ }^{9}$

As análises até então realizadas na dissertação e o contato recorrente com o banco de dados evidenciaram que, diante da necessidade de compreender outras possíveis interpretações da realidade investigada a partir das diversas variáveis de análise do banco de dados, era necessário desenvolver um estudo quantitativo, o que nos possibilitou estabelecer relações causais entre as dimensões analisadas, tanto isoladamente quanto no cruzamento dos dados.

Trata-se, portanto, de uma pesquisa de cunho descritivo e interpretativo, que se concentrou nos dados de um questionário estruturado, ${ }^{10}$ composto de 85 questões, das quais 71 fechadas e 14 abertas. A reflexão sobre a sinopse do survey nacional permite-nos analisar e discutir a organização desses dados em 26 categorias (GESTRADO, 2010). ${ }^{11}$ Todavia, de acordo com nosso objeto de investigação, é possível estabelecer uma nova organização e novas variáveis. Considerando os nossos objetivos, elencamos quatro eixos de análise: Eixo 1 - as condições do docente na fase inicial da carreira; Eixo $2-$ a atual fase da carreira complementando o mesmo enfoque anterior; Eixo 3 - as condições estruturais de trabalho como determinante da saúde; Eixo 4 - a saúde dos trabalhadores docentes de Educação Física.

Para tanto, utilizamos aproximadamente 20 questões do questionário que se relacionavam diretamente com os objetivos deste estudo.

\section{As condições de trabalho nas fases da carreira docente na Educação Física no Espírito Santo}

Tardif e Lessard (2011, p. 24) defendem que a trajetória profissional no âmbito da educação acontece fundamentalmente na escola, instituição historicamente ligada ao progresso da sociedade industrial e, portanto, à sua lógica, sendo "[...] concebida, tanto nas suas formas quanto no conteúdo, estritamente relacionada aos modelos organizacionais do trabalho produtivo e à regulamentação dos comportamentos e atitudes que sustentam a racionalização das sociedades modernas pelo Estado". Os reflexos dessa organização são sentidos, por exemplo, com a redefinição dos papéis

10 O instrumento foi testado com 64 docentes de Belo Horizonte, nos meses de junho e julho de 2009 para os ajustes necessários. Posteriormente, entre setembro e dezembro do mesmo ano, foi aplicado em sete Estados brasileiros, nas escolas selecionadas na amostragem. As entrevistas para elaboração dos questionários foram desenvolvidas na própria unidade escolar em que os sujeitos estavam lotados, por uma equipe de aplicadores de questionários previamente treinados, visando a diminuir as possibilidades de os docentes não responderem ou deixarem perguntas em branco (GESTRADO, 2010).

11 Caracterização dos sujeitos; Rendimentos; Contexto familiar; Ocupação em outras atividades; Formação (compreendendo aqui as subcategorias Formação inicial, Formação continuada e Avaliação da Política Nacional de Formação Docente); Situação funcional; Início das atividades docentes; Valorização profissional; Atividades com alunos com necessidades especiais; Realização de atividades em casa; Condições de trabalho na unidade educacional; Vivência profissional; Preparo para o desenvolvimento das atividades; Gestão escolar; Avaliação do trabalho escolar; Análise do acompanhamento dos pais dos alunos às atividades educacionais de seus filhos; Atividade do professor; Atividades com colegas; Situação na unidade educacional; Interferência no desempenho das atividades; Importância dos objetivos para o trabalho; Relacionamento com sindicatos; Ocupação do tempo livre; Afastamento por licença médica. 
(WITTIZORECKI; MOLINA NETO, 2005), na insatisfação com as condições e resultados do trabalho desenvolvido (BOTH; NASCIMENTO, 2009), nas dicotomias existentes entre função social e função ideal da escola brasileira, na constante submissão do profissional a estímulos estressores oriundos do ambiente físico e das demandas do trabalho (CRUZ; LEMOS, 2005), entre outros.

Apesar das influências do modelo industrial e econômico na consolidação do trabalho docente, defendemos que as especificidades dessa profissão de relações e interações (TARDIF; LESSARD, 2011) não permitem que ela seja compreendida apenas pela lógica industrial. Por essa razão, corroborando o pensamento de Wittizorecki e Molina Neto (2005), acreditamos que o trabalho docente precisa ser compreendido e discutido na perspectiva dos próprios docentes, ou seja, na aproximação com os sujeitos e o espaço de trabalho profissional.

Nesse sentido, vale destacar que estudos, como os de Both, Nascimento e Borgatto (2007), Lemos, Nascimento e Borgatto (2007) e Folle e Nascimento (2008), procuram discutir alguns elementos que auxiliam na compreensão de como se dá e do que é a profissão professor na atualidade, relacionando-os com a estruturação do trabalho, com o tempo na profissão e com as dimensões da carreira docente.

Assumindo a classificação de Huberman (2007), procuramos discutir aspectos das condições de trabalho de docentes de Educação Física do Espírito Santo, contemplando as cinco fases que o autor propõe. Nesse sentido, primeiramente identificamos que, dentre os 87 sujeitos investigados, 22 se encontravam na Fase de Entrada (25,29\%); 15 na Fase de Estabilização (17,24\%); 39 na Fase de Diversifi- cação (44,83\%); 10 na Fase de Serenidade $(11,49 \%)$; e 1 na Fase de Desinvestimento $(1,15 \%)$. Depois, seguimos caracterizando cada fase e discutindo os dados produzidos na pesquisa.

A primeira fase, Fase de Entrada, estava sendo vivida por $25,29 \%$ dos docentes investigados. De acordo com Huberman (2007), geralmente essa fase ocorre dos dois até os três primeiros anos de ensino e é marcada por aspectos contraditórios, caracterizados pela sobrevivência e pela descoberta da/na profissão, que caminham juntos.

[...] O aspecto da 'sobrevivência' traduz o que se chama vulgarmente o 'choque do real', a confrontação inicial com a complexidade da situação profissional: o tactear constante, a preocupação consigo próprio ('Estou-me a aguentar?'), a distância entre os ideais e as realidades quotidianas da sala de aula, a fragmentação do trabalho, a dificuldade em fazer face, simultaneamente, à relação pedagógica e à transmissão de conhecimentos, a oscilação entre relações demasiado íntimas e demasiado distantes, dificuldades com alunos que criam problemas, com material didáctico inadequado, etc. Em contrapartida, o aspecto da 'descoberta' traduz o entusiasmo inicial, a experimentação, a exaltação por estar, finalmente, em situação de responsabilidade (ter a sua sala de aula, os seus alunos, o seu programa), por se sentir colega num determinado corpo profissional (HUBERMAN, 2007, p. 39).

Ao analisarmos como os docentes se sentiam no início da carreira, observamos que esta fase parece ter sido permeada, em maior parte, por experiências positivas, já que $56,3 \%$ declararam sentir-se preparados ou muito preparados em relação ao domínio 
dos conteúdos abordados e à avaliação da aprendizagem; 80,4\% disseram sentir-se da mesma forma com referência à comunicação com os alunos; $75,8 \%$ quanto ao trabalho em equipe/colaboração com os colegas; 79,3\% em relação ao planejamento de suas atividades. Além disso, 86,2\% dos investigados diziam estar preparados ou muito preparados no que se refere ao conhecimento sobre saúde, cuidados e necessidades básicas das crianças/jovens; e $65,5 \%$ dominavam conhecimentos sobre como as crianças/jovens aprendem e se desenvolvem. O estudo de Zucolotto (2012) evidencia que os $19,9 \%$ dos docentes do Espírito Santo (envolvendo todas as áreas de conhecimento), participantes da pesquisa TDEBB, que estavam na fase inicial da carreira, se consideravam razoavelmente preparados em relação ao domínio dos conteúdos abordados e ao domínio dos aspectos administrativos da unidade educacional, demonstrando o preparo dos profissionais investigados para lidar com essas demandas da profissão.

Somando os elevados índices de preparo com outros elementos, como a receptividade na escola pelos próprios pares, discutida em Farias et al. (2008), o "choque com o real" no início da profissão, para os integrantes do estudo, parece ter sido permeado de experiências mais positivas, o que se aproxima da realidade vivida pelos docentes do Estado de Santa Catarina, cuja discussão é realizada no estudo de Both, Nascimento e Borgatto (2007) e demarca uma das possibilidades discutidas por Huberman (2007).

Reconhecemos que essas condições, apesar de mais adequadas, nem sempre se consolidam quando o docente ingressa no seu espaço profissional, pois perpassam outras dimensões que ultrapassam os conhecimentos didático-pedagógicos específicos da disciplina e dos espaços formativos. Exemplificamos com os resultados referentes ao preparo que os docentes apresentavam para lidar com a utilização de novas tecnologias e ao domínio dos aspectos administrativos da unidade educacional. Em ambos os casos, essas foram as dimensões em que o despreparo ou a falta de resposta ocorriam de forma mais acentuada, representando, em ambos os casos, 20,69\% dos sujeitos investigados.

Direcionando o olhar para os outros ciclos, analisamos ainda a atual fase da carreira docente em que os participantes se encontravam. Desconsiderando os dados referentes aos $25,29 \%$ que estavam no momento inicial da carreira, identificamos que $74,71 \%$ dos docentes se encontravam há mais de quatro anos na profissão. Dentre esses, $57,47 \%$ apresentavam despreparo no trato com a tecnologia e com os aspectos administrativos. Esse dado pode apontar a necessidade de investimento na formação inicial e continuada.

A Fase de Estabilização contemplava $17,24 \%$ dos professores investigados. De acordo com Huberman (2007, p. 39-40), ela se designa pelo estado de

[...] 'comprometimento definitivo' ou da 'estabilização' e da 'tomada de possibilidades'. [...] trata-se a um tempo, de uma escolha subjetiva (comprometer-se definitivamente) e de um acto administrativo (a nomeação oficial). Num dado momento, as pessoas 'passam a ser' professores, quer aos seus olhos, quer aos olhos dos outros, sem necessariamente ter de ser por toda a vida, mas ainda assim, por um período de 8 a 10 anos, no mínimo [...]. Na quase totalidade dos estudos empíricos, a 
estabilização precede ligeiramente ou acompanha um sentimento de 'competência' pedagógica crescente.

Esse sentimento de competência apareceu no momento em que os docentes foram interrogados sobre o grau de controle na definição de suas atividades, pois $66,66 \%$ disseram ter muito controle, enquanto $28,66 \%$ afirmaram ter um controle razoável. Da mesma forma, a organização do tempo de trabalho foi analisada por $86,66 \%$ dos docentes como uma dimensão que, nessa fase, há muito ou razoável controle. Os dados reforçam a segurança adquirida com o exercício da profissão (HUBERMAN, 2007), especialmente se relacionados com os resultados do estudo de Folle et al. (2008), ${ }^{12}$ que visou a analisar o nível de qualidade de vida no trabalho dos professores de Educação Física da rede estadual de ensino de Porto Alegre/RS, e concluiu que, dentre as dimensões estudadas, a "Oportunidade futura de crescimento e segurança", tanto para os professores graduados quanto para os pós-graduados, independentemente da classe do magistério a qual pertenciam, representava altos índices de satisfação, ficando atrás apenas da dimensão "Constitucionalismo na organização do trabalho".

Logo após a Estabilização, com $44,83 \%$ representando a maior concentração de docentes numa única fase, identificamos a Fase de Diversificação, que perdura mais ou menos dos 7 aos 25 anos de carreira e se caracteriza por um momento de experimentação.
As pessoas lançam-se, então, numa pequena série de experiências pessoais, diversificando o material didático, os modos de avaliação, a forma de agrupar os alunos, as sequências do programa, etc. Antes da estabilização, as incertezas, as inconsequências e o insucesso geral tendiam de preferência a restringir qualquer tentativa de diversificar a gestão das aulas e a instaurar uma certa rigidez pedagógica [...]. Os professores, nesta fase das suas carreiras, seriam, assim, os mais motivados, os mais dinâmicos, os mais empenhados nas equipes pedagógicas ou nas comissões de reforma (oficiais ou 'selvagens') que surgem em várias escolas (HUBERMAN, 2007, p. 41-42).

O empenho evidencia-se nos elementos que determinam o manejo da disciplina, por exemplo. Enquanto na Fase de Entrada $67,82 \%$ disseram ter um considerável preparo para lidar com o manejo e a didática da disciplina, nesta fase esse percentual subiu para $100 \%$ dos participantes do estudo, destacando o tempo na profissão como fundamental para o aperfeiçoamento dos elementos didáticos do trabalho docente.

Ao questionarmos a importância dos anos de trabalho nessa qualificação, percebemos que, além das experiências profissionais, outros elementos, como condições de trabalho, integração e relevância social da vida no trabalho, atuam concomitantemente e podem contribuir para o aperfeiçoamento de aspectos relacionados com o manejo e a didática do ensino da Educação Física na escola. Em um estudo que visou a investigar a qualidade de vida no trabalho (QVT)

12 Trata-se de um estudo descritivo-exploratório, de caráter transversal, cuja população compreendeu 7.625 professores de Educação Física, sendo selecionada uma amostra de 380 indivíduos, 239 do sexo masculino e 141 do feminino. 
percebida pelos professores de Educação Física da rede estadual do Rio Grande do Sul, considerando os diferentes ciclos de desenvolvimento profissional, Farias et al. (2008) apresentaram algumas pistas que podem nos auxiliar nessa compreensão. Os autores perceberam que essa motivação é impulsionada por razões intrínsecas e extrínsecas, entre as quais destacaram o gosto pela profissão, o desejo de ser professor e a influência de antigos professores. Esses sentimentos positivos são reforçados com o tempo de carreira, pois é nas fases mais avançadas que estão os maiores índices de satisfação, talvez associados à autonomia e ao domínio de aspectos referentes à turma, ao conteúdo e à didática.

Mas será que aquele profissional que ingressou na docência com ideais positivos no sentido de querer estar em formação e de ser um professor comprometido com seu papel social também passa por significativos avanços nesse sentido? Acreditamos que, por ser a docência uma profissão que requer constante formação, inclusive a partir do próprio exercício profissional (NÓVOA, 2007), a qualificação do trabalho é potencializada em seu desenvolvimento, associando a efetivação do componente curricular a um conjunto de fatores, conforme já mencionados.

A penúltima fase é a Serenidade, caracterizada principalmente pela progressão na carreira e por professores cuja faixa etária compreende os 45-55 anos, com menores níveis de ambição e investimento, se comparados com as das fases anteriores, maior tolerância e espontaneidade. É também nesse momento da carreira que o docente apresenta maior serenidade em situações de sala de aulas (HUBERMAN, 2007). Acreditamos que a experiência ${ }^{13}$ oriunda da trajetória na carreira docente é fundamental na consolidação das características dessa fase e na constituição identitária do docente que se faz em um processo dinâmico e contínuo ao longo da carreira.

Foi entre os $11,49 \%$ dos docentes dessa fase que observamos o mais elevado percentual de insatisfação e estagnação com a carreira: $66,6 \%$. Contrapondo o que Huberman (2007) defende, também foi entre os docentes que tinham de 25-35 anos de carreira que identificamos o maior grau de controle sobre a organização do trabalho e a definição das atividades docentes, o que nos leva a indagar se o dia a dia do trabalho, somado às condições concretas em que ele ocorre e ao status social da profissão são fatores decisivos para justificar a insatisfação e a estagnação que demonstrou essa categoria de análise.

Reiteramos que a docência é uma profissão que se encontra em um contexto macrossocial e que o professor é um trabalhador que recebe uma remuneração mensal pelo trabalho que desempenha, em um determinado contexto, cujo local está situado socialmente. Os professores investigados retratam uma contradição

13 Ressaltamos que não estamos nos referindo a toda experiência mas, sim, àquela que "[...] parte do princípio de que o sujeito toma consciência de si e de suas aprendizagens experienciais quando vive, simultaneamente, os papéis de ator e investigador da sua própria história" (JOSSO, 2010, p. 12). Nesse sentido, a experiência formadora implicaria a articulação consciente de atividade, sensibilidade e afetividade de uma representação e/ ou competência que apesar de variar, de acordo com diferentes escalas de importância, não se fundamenta na reprodução de uma mera experiência, mas na formação a partir dela, colocando o professor "[...] em interação consigo mesmo, com os outros, com o meio natural ou com as coisas [...]" (JOSSO, 2010, p. 56). 
da profissão, intensificada pelos anos em serviço, ou seja, ao longo da carreira, conseguem desenvolver-se profissionalmente e oferecer um trabalho mais qualificado, porém saturam-se com as condições precárias das escolas públicas brasileiras e com o baixo prestígio social da profissão, diante das inúmeras dificuldades que enfrentam e dos mais diversos papéis que a escola precisa assumir.

Por fim, a última fase, segundo a classificação, é a do Desinvestimento, que pode ser amargo quando permeado por experiências e sentimentos mais negativos, ou sereno quando observamos o inverso. $\mathrm{Na}$ literatura sobre a temática "A postura geral é, até certo ponto, positiva, as pessoas libertam-se, progressivamente, sem o lamentar, do investimento no trabalho, para consagrar mais tempo a si próprias, aos interesses exteriores à escola e a uma vida social de maior reflexão" (HUBERMAN, 2007, p. 46). Apesar de uma caracterização, o próprio autor reconhece que a existência de uma fase de desinvestimento profissional não está claramente demonstrada nas investigações específicas sobre o ensino (HUBERMAN, 2007).

Em nosso estudo, apenas um docente de Educação Física encontrava-se nessa fase, porém o questionário utilizado não continha elementos suficientes para afirmar se ele estava desenvolvendo seu trabalho com desinteresse ou serenidade, se estava em desinvestimento em suas atividades de ensino ou se o empenho das fases anteriores se mantinha mesmo depois de tantos anos de profissão.

Em uma análise mais ampla que envolve questões sobre todas as fases da carreira, os docentes de Educação Física demonstraram que definir as atividades, assim como definir os conteúdos a serem abordados não se constituem problemas para seu trabalho. As únicas opções que indicaram um certo despreparo se referiram à seleção do material didático $(9,20 \%$ disseram ter pouco preparo e $6,90 \%$ nenhum preparo), ao controle do Projeto Político-Pedagógico da escola $(11,49 \%$ afirmaram ter pouco preparo e $13,79 \%$ nenhum preparo) e ao domínio da tecnologia.

A experiência com o outro pode auxiliar na intensificação das fases, não apenas cronologicamente, mas atribuindo significados a algumas características apresentadas, todavia ressaltamos que tanto as redes municipais investigadas, quanto a rede estadual não apresentam política de acolhimento nas escolas ou ações que fortaleçam a interação entre pares, gestão, alunos e comunidade em geral. Talvez o despreparo pudesse ser sanado com iniciativas dessa natureza.

Ao relacionar satisfação com a profissão e tempo de carreira, percebemos que, em todas as fases/ciclos, a satisfação predominou. Todavia, essa opinião não foi unânime. Aqueles que afirmaram satisfação concordavam que a carreira permitia progressão profissional, enquanto aqueles que registravam insatisfação justificavam o contrário, ou seja, que a carreira não permitia progressão profissional. Os que disseram estar estagnados $(16,6 \%)$ acreditavam que já haviam alcançado a melhor posição que a carreira poderia lhes oferecer, e a soma daqueles que disseram estar insatisfeitos e estagnados foi superior ao número dos que estavam satisfeitos com a profissão.

A progressão profissional parece se constituir em um elemento divisor de opiniões, que se associa diretamente à satisfação. Os dados podem indiciar que a 
maneira como a titulação e o desempenho são utilizados, como parâmetros para a ascensão na carreira, nem sempre é compreendida e avaliada positivamente pelos docentes. Podem indiciar ainda que essa questão merece uma reflexão um pouco mais ampla, já que dentre os professores investigados, $42,5 \%$ não faziam parte do quadro efetivo das redes municipal e estadual de ensino. Uma vez sem vínculo de trabalho, a progressão se limita ao ano de exercício profissional, conforme titulação apresentada no processo seletivo. Dessa forma, a cada seleção, caso não haja certificação atualizada, o docente ocupa o mesmo lugar dos anos anteriores.

\section{Relação trabalho docente e saúde na Educação Física}

O estudo realizado por Santini (2004) com professores de Educação Física da rede municipal de ensino de Porto Alegre contribui para a compreensão da complexidade de elementos que precisam ser levados em conta para discutir a saúde dos trabalhadores docentes. Segundo o autor, vários são os fatores que perpassam essa temática, mas essencialmente eles são divididos em fatores pessoais (idade, gênero, idealismos, personalidade e motivações) e profissionais (divididos em extrínsecos - dimensões física, social e organizacional do trabalho - e intrínsecos - variações ocupacionais, volume de trabalho, autonomia, promoção e desenvolvimento profissional).

Anteriormente, elencamos alguns fatores profissionais de caráter mais intrínseco, relacionados com as fases/ciclos da carreira. Complementando-os, destacamos alguns de natureza mais extrínseca associados a espaços físicos para a Educação Física e condições de infraestrutura das unidades educacionais. Aproximadamente 30\% dos indivíduos investigados avaliaram a quadra de esportes, o parquinho e a área de recreação como espaços insuportáveis e, se considerarmos aqueles que não responderam à questão, esse percentual sobe para cerca de $55 \%$. Ruídos originados na sala de aula $(41,3 \%)$ e ventilação $(40 \%)$ também foram avaliados como condições extrínsecas que impactam negativamente o trabalho. Considerando a soma desses fatores, conforme destacam Wittizorecki e Molina Neto (2005), as escolas tornam-se espaços de dilemas e limitações para o desenvolvimento das aulas de Educação Física.

Além disso, há a intensificação e reestruturação do trabalho do professor na escola, que tem incorporado inúmeras outras atribuições, o que faz emergir uma preocupação com o adoecimento da categoria, explicitada no interesse de estudiosos como Almeida (2008), Cruz e Lemos (2005) e Santini (2004) pela temática. Buscando contribuir para essa discussão, nosso estudo, neste momento, atém-se a tratar da relação trabalho e saúde docente, apresentando outras questões que não apenas determinam as condições de trabalho, mas, segundo nossos autores de referência, estão diretamente relacionadas com o adoecimento na categoria.

Quando pensamos nessa relação, percebemos que, na produção acadêmica, conforme apresenta Duarte (2010), a saúde e o mal-estar docentes são tratados em estudos que abordam as causas mais frequentes de adoecimento, como "[...] Síndrome de Burnout; prevalência de problemas vocais e estresse em professores; condições de vida e trabalho e as consequências sobre a saúde 
mental do professor; implicações do tempo na saúde e no trabalho docente" (DUARTE, 2010, p. 106).

Talvez um aspecto determinante dessas condições de trabalho se refira às questões do instrumento de coleta de dados que tratavam da organização dos "tempos" de trabalho daqueles que atuavam na Educação Física do Espírito Santo, cujo enfoque, neste momento, incide sobre a carga horária semanal do turno de trabalho na instituição participante do estudo, o número de instituições em que atuavam, o tempo de deslocamento entre essas instituições e a necessidade de levar trabalho para casa.

Os dados evidenciaram que a carga horária semanal de trabalho ${ }^{14}$ na instituição participante do estudo, para $71 \%$ dos docentes, não era suficiente para garantir remuneração que correspondesse às suas necessidades financeiras, levando-os a trabalhar em outros turnos, instituições ou até em outras ocupações (apenas 28\% trabaIhavam somente na instituição investigada). Quanto ao número de horas, $17 \%$ tinham até 20 horas de trabalho; $62 \%$, de 20 a 25 horas; $12 \%$, de 30 a 40 horas; e $9 \%$, acima de 40 horas. Não obstante o que discutem Tardif e Lessard (2011), os docentes tinham dupla, tripla e até quádrupla jornada de trabalho, com carga horária e contratos fragmentados, o que pode resultar em consequências penosas para o trabalhador. Exemplificando, trazemos uma condição resultante dessa situação: quanto ao tempo gasto com o deslocamento entre diferentes unidades educacionais, $50 \%$ gastavam até 30 minutos; $34 \%$, de 30 minutos a 1 hora nessa locomoção; $14 \%$, de 1 a 2 horas; e $2 \%$, de 2 a 3 horas. Esse tempo é consideravelmente superior àquele que os demais professores sujeitos da pesquisa do Espírito Santo disseram destinar a esse deslocamento: $43 \%$ gastavam até 30 minutos e os demais faziam em menor tempo (FERREIRA; VENTORIM; COCO; 2012).

Sobre o fato de levar trabalho da unidade educacional para casa, $100 \%$ dos professores de Educação Física disseram destinar de cinco $(63,2 \%)$ a mais de 30 horas $(24,1 \%)$ semanais do seu tempo em casa para atividades referentes ao seu trabalho. Esse dado demonstra que, mesmo lidando com o saber fazer, ou seja, com as particularidades da área de conhecimento, cujo objeto de ensino e aprendizagem envolve o movimento, o componente curricular tem exigido do docente organizações e sistematizações de trabalho que também não se esgotam no momento da aula.

A constituição desses "tempos" pode ser compreendida melhor quando analisamos a remuneração do grupo investigado: $72,4 \%$ recebiam de um a quatro salários mínimos. Para Ferreira, Ventorim e Coco (2012, p. 31), quanto às condições de trabalho docente no Espírito Santo, "O maior agravante diz respeito à faixa salarial informada pelos trabalhadores docentes pesquisados, pois cerca de $80 \%$ informaram que recebem de 1 a 4 salários mínimos".

Todas essas condições se colocam como desafios para os trabalhadores que são levados a incorporar novas atribuições e que, cotidianamente, são submetidos a condições de trabalho, muitas vezes incom-

14 Os dados apresentados evidenciam a carga horária de trabalho no turno em que a pesquisa foi realizada. Todo o questionário foi desenvolvido nessa perspectiva. 
patíveis com as suas necessidades de saúde, levando-os, por exemplo, a situações mais extremas, como o afastamento do trabalho.

Com base na classificação dos ciclos/fases/estádios da carreira (HUBER-
MAN, 2007), a Tabela 1 apresenta a incidência dos afastamentos entre os docentes investigados.

Tabela 1 - Relação afastamento e ciclo de carreira profissional dos docentes de Educação Física

\begin{tabular}{lcccccc}
\hline \multirow{2}{*}{$\begin{array}{c}\text { Ciclos/fases da } \\
\text { carreira profissional }\end{array}$} & \multicolumn{2}{c}{ Frequência } & \multicolumn{2}{c}{ Percentual (\%) } & Nr $\begin{array}{c}\text { Percentual } \\
\text { acumulativo (\%) }\end{array}$ \\
\cline { 2 - 5 } & Sim & Não & Sim & Não & & \\
\hline De 0 a 3 anos & 13 & 9 & 15,9 & 10,4 & 0 & 26,3 \\
De 3 a 6 anos & 8 & 6 & 9,2 & 6,9 & 1 & 42,4 \\
De 6 a 25 anos & 21 & 18 & 24,2 & 20,7 & 0 & 87,3 \\
De 26 a 35 anos & 6 & 4 & 6,9 & 4,6 & 0 & 98,8 \\
Mais de 35 anos & 0 & 1 & 0,0 & 1,2 & 0 & 100 \\
Total & 48 & 38 & 56,2 & 43,8 & & 100 \\
\hline
\end{tabular}

Fonte: Os autores.

NOTA: NR = não respondeu.

Percebemos que $55,3 \%$ dos docentes de Educação Física investigados se afastaram do trabalho por licença médica no período analisado, enquanto $33 \%$ de todos os sujeitos investigados do Estado se afastaram no mesmo período. É interessante ressaltar que o número de afastamento, quando comparado com o das fases/ciclos/ estádios da carreira, apresentou-se elevado mesmo na fase de entrada. Esse fato leva-nos a pensar que a Síndrome do Esgotamento Profissional pode acometer também profissionais recém-formados e relativamente novos na profissão. Quanto a isso, as questões que nos inquietam neste momento são as seguintes: será que realmente o início da carreira desses profissionais foi permeado por momentos mais positivos, conforme discutido no início deste estudo?
Quais outros fatores, para além dos que exploramos, precisam ser considerados para discutir o início da carreira docente na Educação Física?

Com percentuais muito próximos daqueles apresentados em Ferreira, Ventorim e Coco (2012), as principais causas dos afastamentos foram as seguintes: estresse $(17 \%)$; depressão, ansiedade ou nervosismo $(15 \%)$; problemas com a voz $(11 \%)$; e doenças musculoesqueléticas ( $9 \%$ ). Foram apontados, ainda, outros motivos, como cirurgias, gravidez e licença-maternidade, acompanhamento de parentes, problemas respiratórios (pneumonia e resfriados), torção de pé ou joelho e dengue (48\%). Quanto ao estresse, Silveira et al. (2014) afirmam que ele é resultado de demandas do trabalho, como lidar com a classe e 
manter a disciplina, desenvolver as tarefas, organizar os grupos de alunos, ajudando-os a superar os problemas de comportamento e relacionamento, trabalhar com o conteúdo de forma que garanta a comunicação das aprendizagens necessárias. A aproximação com a escola brasileira na atualidade indica que o profissional se depara com elementos levantados por Silveira et al. (2014), que estão presentes no dia a dia do trabalho docente com intensidades bastante variadas.

Quanto ao tempo, os afastamentos variaram de uma semana $(44,7 \%)$ a mais de um mês $(18,4 \%)$ e, em alguns casos, levaram à readaptação de função $(7,9 \%)$ e à redução do valor da remuneração $(5,4 \%$ ) Esses fatores reforçam o entendimento de que "[...] a saúde também está referenciada a um meio social, histórico, político, cultural, que remete a uma história coletiva condensada e presente nas regras de trabalho", conforme defendem Mascarello e Barros (2007, p.115).

Essas dimensões com a "[...] perda da motivação, desamparo, desesperança, passividade, alienação, depressão, fadiga e estresse geram o pressuposto de que esses elementos levam os professores, em casos extremos, à perda total da capacidade de trabalho [...]" (SANTINI, 2004, p. 14). Entre os docentes investigados, não houve indícios de progressão ou agravamentos dos problemas de saúde identificados, porém destacamos que estresse, depressão, ansiedade, nervosismo e até problemas com a voz necessitam de cuidados e acompanhamentos especiais, podendo resultar em situações extremas, já que essas características se assemelham aos sintomas da Síndrome de Burnout ou Síndrome de Esgotamento Profissional, ${ }^{15}$ cuja temática aparece em Silveira et al. (2014), Cruz e Lemos (2005), Santini e Molina Neto (2005) e Santini $(2004 ; 2003)$.

A Síndrome de Esgotamento Profissional evidenciou-se efetivamente nos anos 1970, quando surgiram instrumentos capazes de perceber os sentimentos de esgotamento, desânimo e desmotivação causados pelo cansaço e constante ajustamento da personalidade às condições de trabalho nas profissões relacionadas com o "cuidar", como Enfermagem, Medicina, Psicologia, Educação e Assistência Social (SANTINI, 2004). Para o autor, os profissionais que sofrem com essa síndrome passam por exaustão emocional (sensação física e mental de esgotamento), despersonalização (irritabilidade, ansiedade, desmotivação, descaso com os resultados a alcançar, ironia e indiferença em relação às pessoas) e diminuição da realização pessoal no trabalho (infelicidade e insatisfação profissional).

Reconhecendo outros elementos nesse processo, a investigação abordou fatores associados à condição e utilização da voz, incidência de processo inflamatório, infeccioso ou alérgico nas vias superiores e utilização constante de medicamento. Quanto à voz, 25,3\% dos docentes de Educação Física afirmaram que, de vez em quando, sentiam piora na qualidade da voz,

15 No Brasil, utilizamos o termo Síndrome de Burnout como sinônimo da Síndrome do Esgotamento Profissional (SEP) desde 1999, quando o então ministro de Estado da Saúde, Sr. José Serra, ao instituir o ANEXO 2 do Decreto n. ${ }^{\circ} 3.048$, da Portaria n. ${ }^{\circ} 1.339$, de 18 de novembro de 1999 , que trata das 14 classificações de doenças relacionadas com o trabalho, a ser adotada como referência dos agravos originados no processo de trabalho no Sistema Único de Saúde, assim se referiu à síndrome. 
$19,5 \%$ disseram sentir isso diariamente, enquanto $54 \%$ registraram que não sentiam piora na qualidade da voz.

Percebemos que $31 \%$ utilizam a voz em alguma outra atividade fora da sala de aula, o que constituiu um fator agravante da piora da sua qualidade. Ao serem questionados se haviam apresentado processo inflamatório, infeccioso ou alérgico nas vias aéreas superiores (sinusite, rinite, amigdalite ou faringite) nas últimas duas semanas, $65,5 \%$ disseram que não, 33,3\% que sim e $1,1 \%$ não respondeu. No estudo de Ferreira, Ventorim e Coco (2012), 35\% dos respondentes foram acometidos por esses problemas.

Também foram contempladas questões que buscaram identificar se os docentes possuíam plano de saúde e como era o custeio desse plano. Percebemos que $76,7 \%$ possuem plano de saúde e $23,3 \%$ não possuem. Apenas 10,6\% não pagam nada pelo plano, enquanto $21,1 \%$ arcam com parte dos custos e $51,7 \%$ o pagam integralmente.

A aproximação com as condições de trabalho e carreira docente possibilita-nos perceber que o desgaste, que muitas vezes leva ao afastamento, pode estar relacionado com inúmeros fatores, entre os quais as limitações da formação acadêmica, os constantes desafios que derivam do próprio trabalho e o acúmulo de atividades. Todavia, isoladamente, esses elementos não justificam o número significativo de problemas relacionados com a saúde registrado pelos docentes.

Os dados não permitem que estabeleçamos uma relação direta entre as condições específicas de trabalho da Educação Física e agravantes para a saúde do trabalhador, mas o fato de a recorrência dos afastamentos ser superior a dos demais professores das outras áreas de conhecimento pode trazer indicativos de que trabalhar em espaços abertos, com conteúdos voltados para o movimento, impactam de maneira diferente a nossa saúde. Além deles, alguns questionamentos se fazem necessários: as condições precárias de espaço físico e, consequentemente, o improviso constante se consolidam como fatores desmotivantes para a área? Há impactos? O professor tem buscado meios para amenizá-los? Por outro lado, mesmo diante das circunstâncias impostas pelas especificidades da área, as condições da voz, por exemplo, não pareceram agravadas. Talvez precisemos refletir um pouco mais sobre esses indicativos e aprofundar essa discussão em estudos futuros.

De qualquer forma, alguns pesquisadores, como Almeida (2008), já direcionam o foco de suas investigações para o levantamento das saídas que os professores encontram para não adoecer e continuar trabalhando, mesmo diante da situação apresentada neste estudo com a qual dialogamos.

\section{CONSIDERAÇÕES FINAIS}

A discussão sobre condições de trabalho, tempo de carreira e dimensões da saúde dos professores de Educação Física no Espírito Santo possibilitou-nos estabelecer alguns apontamentos como considerações para este final. Primeiramente, destacamos que os estudos com os quais dialogamos evidenciaram um aumento crescente de interesse por investigações que tratam das condições de trabalho, de carreira e de saúde docente na educação e na Educação Física, justificadas, ao nosso ver, pela complexidade da temática. 
Os problemas referentes à de saúde dos docentes de Educação Física investigados não estão diretamente relacionados com as fases/ciclos/estádios da carreira docente, ou seja, professores com mais tempo de trabalho (carreira) não adoecem mais que aqueles que estão iniciando a atividade docente. Ao contrário, o que nos chamou a atenção foi o fato de os docentes iniciantes parecerem estar mais propícios a fatores que podem levar ao adoecimento do que aqueles que estão na carreira há mais tempo. Esse dado nos remete a outras análises que merecem ser exploradas em estudos futuros, mas que já apontam algumas questões, tais como: de que maneira os cursos de formação têm preparado os professores para os desafios da escola de hoje? Como ensinam a lidar com tamanha complexidade? Em que medida a relação teoria e prática se consolida diante das características do campo de atuação profissional?

A decisão por utilizar a classificação de Huberman (2007) na interpretação do questionário analisado se deu pela necessidade de dialogarmos com estudos já realizados na mesma perspectiva, cujo enfoque parece ganhar campo nos últimos anos. Todavia, reconhecemos que não é possível compreender a carreira como um conjunto de acontecimentos uniformes para todos os envolvidos, já que estamos lidando com sujeitos docentes singulares e esse parâmetro nos leva à necessidade de compreendermos outros elementos condizentes com fases e fatores tanto profissionais quanto pessoais. Ao optarmos pela classificação de Huberman (2007), sentimo-nos provocados às reflexões da consolidação do trabalho e da carreira, compreendendo quão singulares podem ser esses processos e como eles impactam outras dimensões, como a saúde e o mal-estar docentes. Para esses últimos, acreditamos que as condições de trabalho, independentemente do tempo de carreira, podem ser determinantes para a saúde do trabalhador, principalmente se associarmos os fatores intrínsecos e extrínsecos apresentados por Santini (2005).

Remetendo-nos ao componente curricular Educação Física, destacamos ainda que, conforme discutido por Molina Neto (1997), a especificidade da área demanda uma organização e desenvolvimento do trabalho, facilmente visualizados nas particularidades do material e espaços físicos necessários e, muitas vezes, não disponíveis e acessíveis ao docente. Não há como desconsiderarmos que as condições de trabalho na área poderiam (e podem) ser agravantes de alguns problemas de doença do docente de Educação Física, como problemas relacionados com a voz, já que o espaço físico onde geralmente ocorrem as aulas é amplo e aberto, diferentemente das salas de aula. Todavia, no universo investigado, não houve elementos suficientes que comprovassem essa relação ou que associassem a qualidade da voz ao tempo de carreira. A experiência acumulada na área possibilita-nos afirmar, por exemplo, que o professor de Educação Física muito se envolve com questões políticas da unidade educacional, geralmente assumindo cargos de gestão, mas não nos permite dizer que somos a categoria que mais adoece.

De forma geral, o adoecimento do professor é resultado de processos bastante complexos, que apresentam uma dimensão tanto individual quanto coletiva, principalmente, permeadas por fatores intrínsecos e extrínsecos à carreira e ao trabalho. Evidenciamos o quão relevantes e plurais são esses elementos, que precisam ser considerados 
em estudos sobre a temática.

Podemos concluir que receber uma remuneração equiparada com o trabalho desenvolvido, perceber um reconhecimento social da profissão, ter condições de realizar, de forma mais tranquila, as refeições diárias, precisar levar menos trabalho para casa e tantos outros elementos apresentados neste estudo impactariam as condições de trabalho do professor e talvez evitassem processos futuros de adoecimentos. Ao mesmo tempo, compreendendo que o aspecto profissional e o pessoal não se separam (NÓVOA, 1992), o indivíduo precisa ser cuidado também como pessoa.

Assim, a relação da condição de trabalho com o tempo de carreira e a saúde é imprescindível para compreendermos que o adoecimento na profissão docente é fruto de um complexo conjunto de fatores que perpassam o momento da aula, abrangendo questões pedagógicas, novas atribuições da profissão e, ainda, dimensões pessoais do profissional.

Por fim, ressaltamos a relevância de estudos futuros que busquem investigar o acolhimento dos professores iniciantes na escola, tanto daqueles em início de carreira, quanto dos que são levados, anualmente, a se reestruturar em uma unidade educacional diferente após os processos seletivos de designação temporária.

\section{REFERÊNCIAS}

ALMEIDA, U. R. Nas trilhas da atividade docente: análise da relação saúdetrabalho de professores de educação física no cotidiano escolar. 2008. Dissertação (Mestrado em Educação Física). Universidade Federal do Espírito
Santo, Centro de Educação Física e Desportos. Vitória/ES, 2008.

BOTH, J.; NASCIMENTO, J. V. Intervenção profissional na educação física escolar: considerações sobre o trabalho docente.

Revista Movimento, v. 15, n. 2, p. 169186, abr./jun. 2009.

BOTH, J.; NASCIMENTO, J. V.; BORGATTO, A. F. Estilo de vida dos professores de educação física ao longo da carreira docente no Estado de Santa Catarina. Revista Brasileira Atividade Física \& Saúde, v. 12, n. 3, p. 54-64, 2007.

CRUZ, R. M.; LEMOS, J. C. Atividade docente, condições de trabalho e processos de saúde. Motrivivência, ano XVII, n. 24, p. 59-80, jun./2005.

DUARTE, A. et al. Envolvimento docente na interpretação do seu trabalho: uma estratégia metodológica. Cadernos de Pesquisa, São Paulo, v. 38, n. 133, p. 221-236, jan./abr. 2008.

DUARTE, A. A produção acadêmica sobre trabalho docente na educação básica no Brasil: 1987-2007. Educar em Revista, Curitiba, Brasil, n. 1, p. 101-117, 2010. Número Especial.

FARIAS, G. O. et. al. Carreira docente em educação física: uma abordagem sobre a qualidade de vida no trabalho de professores da rede estadual de ensino do Rio Grande do Sul. Revista de Educação Física/UEM, v. 19, n. 1, p. 11-22, 1. trim. 2008.

FERREIRA, E. B.; VENTORIM, S.; COCO, V. O trabalhador docente no Espírito Santo: aproximações gerais sobre o perfil e suas condições de trabalho. In: FERREIRA, E.; OLIVEIRA, D. A.; VIEIRA, L. F. (Org.). O trabalho docente na educação básica: o Espírito Santo em questão. Belo Horizonte: Fino Traço, 2012. 
FOLLE A. et. al. Carreira no magistério e o nível de qualidade de vida no trabalho docente em educação física. Revista Motriz, v. 14, n. 3, p. 210-221, jul./ set. 2008.

FOLLE, A.; NASCIMENTO, J. V. Estudos sobre desenvolvimento profissional: da escolha à ruptura da carreira docente. Revista da Educação Física/UEM, v. 19, n. 4. 2008.

GRUPO DE ESTUDOS SOBRE POLÍTICA EDUCACIONAL E TRABALHO DOCENTE DA UNIVERSIDADE FEDERAL DE MINAS GERAIS (GESTRADO), Pesquisa trabalho docente na educação básica no Brasil: sinopse do survey nacional. Universidade Federal de Minas Gerais, Grupo de Estudos Sobre Política Educacional e Trabalho Docente. Belo Horizonte, 2010.

HUBERMAN, M. O ciclo de vida profissional dos professores. In: NÓVOA, A. (Org.). Vidas de professores. 2. ed. Porto: Editora Porto, 2007. p. 31-61.

JOSSO, Marie-Christine. Experiências de vida e formação. 2. ed. Natal, RN: EDUFRN; São Paulo: Paulus, 2010.

LEMOS, C. A. F.; NASCIMENTO, J. V.; BORGATTO, A. F. Parâmetros individuais e sócioambientais da qualidade de vida percebida na carreira docente em educação física. Revista Brasileira de Educação Física e Esporte, v. 21, n. 2, p. 81-93, abr./jun. 2007.

MASCARELLO, M. R. P.; BARROS, M. E. B. Nos fios de Ariádine: cartografia da relação saúde-trabalho numa escola pública de Vitória-ES. Revista Brasileira de Educação, Rio de Janeiro: Anped, v. 12, n. 34, p. 104-119, jan./abr. 2007. NÓVOA, A. (Org). Os professores e a sua formação. Lisboa: Instituto de Inovação Educacional, 1992.
. Os professores e as histórias da sua vida. In: NÓVOA, A. (Org.). Vidas de professores. 2. ed. Lisboa: Editora Porto, 2007. p. 11-30.

MOLINA NETO, V. A cultura do professorado de educação física nas escolas públicas de Porto Alegre. Movimento, Porto Alegre, ano 4, n. 7, p. 34-42, 1997/2.

OLIVEIRA, D. A. A reestruturação do trabalho docente: precarização e flexibilização. Educação e Sociedade. Campinas, v. 25, n. 89, p. 1127-1144, set./Dez. 2004.

OLIVEIRA, D. A. et al. Trabalho docente na educação básica no Brasil. Belo Horizonte: Gestrado/UFMG, 2009.

OLIVEIRA, D. A.; VIEIRA, L. M. F. Sinopse do survey nacional: relatório da pesquisa nacional. Trabalho docente na educação básica no Brasil. Belo Horizonte: Gestrado/UFMG, 2010.

POZZATTI, M. Trabalho docente na educação física no Espírito Santo. 2012. Dissertação (Mestrado em Educação Física). Universidade Federal do Espírito Santo, Curso de Educação Física, Centro de Educação Física e Desportos. Vitória/ ES, 2012.

QUEIROZ, L. R. S. Pesquisa quantitativa e pesquisa qualitativa: perspectivas para o campo da etnomusicologia. Claves, n. 2, p. 87-98, nov. 2006.

SANTINI. J. A síndrome do esgotamento profissional: o "abandono" da carreira docente pelos professores de educação física da rede municipal de ensino de Porto Alegre. 2004. Dissertação (Mestrado em Ciência do Movimento Humano) - Universidade Federal do Rio Grande do Sul. Escola de Educação Física. Porto Alegre, 2004. 
SANTINI, J. et al. A síndrome do esgotamento profissional: o "abandono" da carreira docente dos professores de educação física da rede municipal de ensino de Porto Alegre. In: CONGRESSO BRASILEIRO DE CIÊNCIAS DO ESPORTE, 14. e CONGRESSO INTERNACIONAL DE CIÊNCIAS DO ESPORTE, 1., 2005, Porto Alegre. Anais... Universidade Federal do Rio Grande do Sul: Porto Alegre, 2005, CD-ROM.

. O processo de abandono da carreira docente dos professores de educação física da rede municipal de ensino de Porto Alegre: a síndrome do esgotamento profissional (SEP), um estudo introdutório. In: CONGRESSO BRASILEIRO DE CIÊNCIAS DO ESPORTE, 13., 2003, Caxambu-MG. Anais... Caxambu, 2003, CD-ROM.

SANTINI, J.; MOLINA NETO, V. A síndrome do esgotamento profissional em professores de educação física: um estudo na rede municipal de ensino de Porto Alegre. Revista Brasileira de Educação Física e Esporte, São Paulo, v. 3, n. 19, p. 209-222, 2005.
SILVEIRA, K. A. et al. Estresse e enfrentamento em professores: uma análise da literatura. Educação em Revista, Belo Horizonte, v. 30, n. 4, p. 15-36, dez./2014.

TARDIF, M. Saberes docentes e formação profissional. Petrópolis: Vozes, 2002.

TARDIF, M. LESSARD, C. O trabalho docente: elementos para uma teoria da docência como profissão de interações humanas. 6. ed. Petrópolis/RJ: Vozes, 2011.

WITTIZORECKI, E. S.; MOLINA NETO. V. O trabalho docente dos professores de educação física na rede municipal de ensino de Porto Alegre. Revista Movimento, Porto Alegre, v. 11, n. 1, p. 47-70, jan./abr. 2005.

ZUCOLOTTO, V. M. Trabalhadores docentes iniciantes no Espírito Santo: perspectivas da carreira. In: BARTOLOZZI, E.; OLIVEIRA, D. A.; VIEIRA, L. F. (Org.). O trabalho docente na educação básica: o Espírito Santo em questão. Belo Horizonte: Fino Traço, 2012. p. 197-216. 
WORKING CONDITIONS, CAREER TIME AND EDUCATION TEACHER HEALTH PHYSICAL DIMENSIONS OF THE ESPIRITO SANTO

\begin{abstract}
Discusses working conditions, career time and health dimensions of 87 physical education teachers working in five municipalities of the Espirito Santo (Guarapari, Nova Venecia, Santa Teresa, Viana and Vitoria), participants of the survey from national research Teaching Work in basic education in Brazil. This is a quantitative and qualitative study of descriptive and interpretative character, which is based on the classification of cycles / phases / stages of teacher career Huberman (2007) and dialogues, especially with Santini $(2004 ; 2005)$ and Almeida (2008). Concludes that the relationship between working conditions and career time, taken in isolation, does not determine the health and malaise of the teaching professional and that this process is complex, depending on a set of factors involving pedagogical issues, professional and personal.
\end{abstract}

Keywords: Physical Education Teacher; Teaching Condition; Health

CONDICIONES DE TRABAJO, TIEMPO DE CARRERA Y DIMENSIONES DE LA SALUD DE LOS MAESTROS DE EDUCACIÓN FÍSICA DEL ESPÍRITO SANTO

\title{
RESUMEN
}

Discute las condiciones del trabajo, tiempo de carrera y dimensiones de la salud de 87 profesores de educación física que trabajan en cinco municipios de Espírito Santo (Guarapari, Nova Venécia, Santa Teresa, Viana e Vitória), participantes del survey de la pesquisa nacional Trabajo Docente en la educación básica de Brasil. Se trata de un estudio cuantitativo y cualitativo de carácter descriptivo y interpretativo, que se basa en la clasificación de los ciclos/faes/etapas de Huberman (2007) y los diálogos, sobre todo con Santini $(2004 ; 2005)$ y Almeida (2008). Concluye que la relacción entre las condiciones de trabajo y el tiempo de carrera, tomado aisladamente, no determinan la salud y el malestar del profesión docente y que este proceso es complejo, depende de un conjunto de factores que involucran cuestiones pedagógicas, profesionales y personales,

Palabras clave: Profesor de Educación Física; Condición Docente; Salud

Recebido em: abril/2015 Aprovado em: novembro/2015 